\title{
Impact of Electron Beam Irradiation on Thermoplastic Polyurethanes Unraveled by Thermal Field-Flow Fractionation
}

\author{
Martin Geisler a, b, Tuhin Subhra Pal c, Kerstin Arnhold a, Mikhail Malanin a,

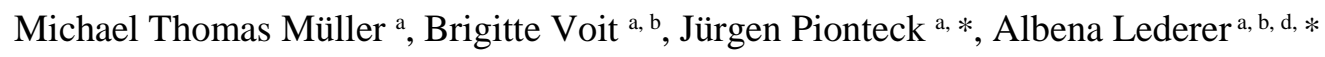 \\ ${ }^{a}$ Leibniz-Institut für Polymerforschung Dresden e. V., Hohe Str. 6, 01069 Germany \\ b Faculty of Chemistry and Food Chemistry, Technische Universität Dresden, 01062 Dresden, Germany \\ c Rubber Technology Centre, Indian Institute of Technology, Kharagpur, 721302 West Bengal, India \\ d Department of Chemistry and Polymer Science, Stellenbosch University, Private Bag X1, Matieland 7602, South \\ Africa \\ *Email of corresponding authors: lederer@ipfdd.de, pionteck@ipfdd.de
}

\begin{abstract}
The impact of electron beam irradiation on thermoplastic polyurethane material was studied for both an aliphatic and an aromatic polyurethane with equal amount of hard and soft segments. Irradiation doses up to $300 \mathrm{kGy}$ at room temperature and at $100{ }^{\circ} \mathrm{C}$ were applied. Changes in chemical structure, molar mass and size were assessed using infrared spectroscopy, differential scanning calorimetry, size exclusion chromatography and thermal field flow fractionation. Material alterations were correlated with trends regarding to degradation, crosslinking or branching changes. Thereby, limits of characterization by size exclusion chromatography are addressed and amended by thermal field-flow fractionation studies. In addition, a thermophoretic analysis has been carried out complementary to the portfolio of analytical methods applied in this work.
\end{abstract}

\section{Introduction}

The impact of irradiation on polymer materials is a research field of great interest and has been widely studied in the past with the aim either to make materials more durable against environmental influences such as UV light ${ }^{1,2}$ or to alter or improve material properties with regard to process engineering. ${ }^{3,4}$ One polymer class being studied is thermoplastic polyurethane (TPU), which represents linear segmented block copolymers containing hard segments (adduct of di-isocyanate and small glycols as chain extender) and soft segments (polyester, polyether, etc.). These segments are connected by means of urethane linkages, which either mix or segregate depending on chemical composition and produce homogeneous or phase separated morphologies. ${ }^{5,6} \mathrm{~A}$ comprehensive introduction into irradiation on polymers in general and with focus on TPU is given by Adem, et al. ${ }^{7}$

So far, all studies dealing with irradiation of TPU focus on chemical alteration investigated by spectroscopy, ${ }^{2,8,9}$ crystallization changes monitored by diffraction techniques and thermal analysis ${ }^{9-11}$ and property changes by mechanical analysis. ${ }^{12,13}$ Only few studies take the changes in molar mass into account monitored by simple molar mass determination by means of size exclusion chromatography (SEC) with standard calibration ${ }^{14-17}$ or by absolute molar mass measurement by SEC coupling to multi- 
angle light scattering (MALS). ${ }^{18}$ However, using SEC, one has to be aware of some analytical challenges which may occur, like delayed elution behavior ${ }^{19}$ or mixed elution due to branching or fraction of high molar masses beyond the separation range of SEC, which are generated by crosslinking. ${ }^{20}$ In particular, for SEC with standard calibration used in this context, significant errors must be considered. Thus, our aim in this study is to apply thermal field flow fractionation (ThFFF), a channel-based separation technique, as an alternative to SEC to get a comprehensive overview on changes in size and topology of the polymers causing different bulk, mechanical or thermodynamic properties, which cannot be followed in-depth by spectroscopic methods or thermal analysis only. This type of separation relies on the retention of analytes in an empty flat ribbon-like channel due to a response on a separation force field applied perpendicular to the flow direction. Depending on the nature of the force field, a separation e. g. according to hydrodynamic size ( $\mathrm{AF}_{4}$ ), effective mass (SdFFF), electrophoretic mobility (E $\left.\ell F F F\right)$ or thermal diffusion (ThFFF) can be realized. ${ }^{21}$ For this study we have chosen ThFFF since this separation technique can be highly selective for changes in the polymer's topology ${ }^{22-24}$ and/or chemical composition. ${ }^{25^{-}}$

${ }^{29}$ Details on the basic separation principle are given elsewhere ${ }^{21,30}$ and in the supporting information (SI, section 1). FFF is usually coupled to a series of detectors (MALS, dRI, UV, online dynamic scattering or offline FTIR), ${ }^{31-35}$ though, the analysis of the separation itself contains already useful information. This is because the measurement of the retention ratio $R$ (void time over retention time) at given field strength allows the determination of the physicochemical parameter describing the response to the force field. For ThFFF, this response is described by the Soret coefficient $S_{T}$, which is the ratio of thermal and translational diffusion. ${ }^{36,37}$ Thermal diffusion is mainly influenced by the polymer solvent interaction ${ }^{38,39}$ and by the effective length of a linear polymer segment, respectively, ${ }^{23,40}$ whereas the translational diffusion at equal conditions depends to a great extent on the hydrodynamic size of the analyte. ${ }^{41}$ Consequently, in combination with the associated analytical tool such as thermal analysis and FTIR spectroscopy, $S_{T}$ is accounted to be a suitable parameter for structural characterization within this study.

\section{Experimental}

The TPU samples used in this study were L780D10 (aliphatic polyester-TPU, assigned as Aliph-TPU) of the composition $4,4^{\prime}$-dicyclohexylmethane diisocyanate $\left(\mathrm{H}_{12} \mathrm{MDI}\right)$ copolymerized with 1,4-butane diol (BD) and a segment of poly(1,6-hexylene adipate), and C74D50 (aromatic polyester-TPU, assigned as Ar-TPU) composed of diphenylmethane diisocyanate (MDI), BD and poly(1,4-butylene adipate). Both TPU are commercial products by BASF Polyurethanes $\mathrm{GmbH}$. The structures and further experimental details are given in the SI (Fig. S9, SI and sect. 2).

\section{Results and discussion}

We have chosen an aliphatic and an aromatic TPU with comparable hard- and soft segment composition (confirmed by ${ }^{1} \mathrm{H}$ - and ${ }^{13} \mathrm{C}-\mathrm{NMR}$, see SI, Fig. S9). In the case of aliphatic TPU a temperature dependency during electron beam irradiation has been already investigated revealing an almost negligible effect of the irradiation temperature on the material alterations observed. ${ }^{7}$ However, for aromatic TPU such an 
investigation has not been reported yet. Therefore, the irradiation studies of the aromatic TPU were performed for irradiation temperatures at room temperature (RT) and $100{ }^{\circ} \mathrm{C}$, whereas the aliphatic TPU study was done solely for room temperature.

\subsection{ATR-FTIR analysis}

In In the ATR-FTIR spectra of both materials, the typical bands of a regular TPU are found (see Fig. 1). Both specimen spectra contain the broad bands of $\mathrm{N}-\mathrm{H}$ stretching vibrations at $3320 \mathrm{~cm}^{-1}$ (amide A), of the asymmetrical and symmetrical C-H stretching vibrations $2925 \mathrm{~cm}^{-1}$ and $2850 \mathrm{~cm}^{-1}$ of methylene groups of aliphatic chains, followed by the amide I band (around $1700 \mathrm{~cm}^{-1}$ ), amide II (around $1530 \mathrm{~cm}^{-}$ $\left.{ }^{1}\right)$, amide III $\left(1220 \mathrm{~cm}^{-1}\right)$ and amide IV $\left(78 \mathrm{o} \mathrm{cm}^{-1}\right)$. Ar-TPU shows additionally remarkable specific bands of $\mathrm{C}=\mathrm{C}$ aromatic ring stretching vibrations (at $1595 \mathrm{~cm}^{-1}$ and $1410 \mathrm{~cm}^{-1}$ ), of aromatic $\mathrm{C}-\mathrm{N}$ stretching vibration at $1307 \mathrm{~cm}^{-1},{ }^{42}$ and at 815 and $751 \mathrm{~cm}^{-1}$ (C-H out of plane bending vibrations). ${ }^{43-45}$ There are also additional bands at 2960 and $2873 \mathrm{~cm}^{-1}$ assignable to methylene groups (asymmetrical and symmetrical $\mathrm{C}-\mathrm{H}$ stretching vibrations) adjacent to butanediol-adipate functionality. ${ }^{46}$ Both TPUs contain bands of $\mathrm{C}-\mathrm{O}-\mathrm{C}$ stretching vibrations in the range $1100-1000 \mathrm{~cm}^{-1}$ (as a part of urethane group ${ }^{44,67}$ adjacent to the linear aliphatic chains of extenders in both hard and soft segment and simultaneously as stretching C-O-C vibration of ester group in soft segment). ${ }^{42,45}$ In contrast to Aliph-TPU, the spectrum of Ar-TPU irradiation exhibits two distinct bands in the region of amide I band, what are assigned to free carbonyl groups $\left(1725 \mathrm{~cm}^{-1}\right)$ and hydrogen-bonded $\left(1701 \mathrm{~cm}^{-1}\right) \cdot{ }^{47}$ In the case of Aliph-TPU the band of free $\mathrm{C}=\mathrm{O}$ groups is only like a shoulder, what reflects higher amount of hydrogen bonding, i.e. lower amount of free urethane groups in it initially. For our systems investigated in this study, the applied doses of the electron beam irradiation had in general only slight impact onto the materials. Nevertheless, the intensity changes for amide I/II/III and other bands of urethane group and bands of methylene group can be seen, but their dynamics is a bit different.

Already the lowest investigated irradiation dose (25 kGy) yielded significant alterations in AliphTPU on the molecular level as can be seen in the vibrational spectra: the amide I, II and III bands in the spectrum of Aliph-TPU decrease in intensity. Simultaneously, the bands of $\mathrm{C}-\mathrm{H}$ and $\mathrm{N}-\mathrm{H}$ stretching vibrations (Fig. 1, insets A1, B1 and A2, B2) become more intensive. This may be explained by induced chain scission/urethane group degradation in the hard segments and formation of primary amines. ${ }^{7}$ Simultaneously, the broadening of amide I on the left band side at around $1800 \mathrm{~cm}^{-1}$ indicates presence of non-associated carboxylic acid groups. ${ }^{45}$ The probability to form primary amines and carboxylic acid as a irradiation caused degradation result of TPU was reported previously ${ }^{2,7,44}$ and may occur even under vacuum ${ }^{48}$. Elevated irradiation dose (50 kGy and higher) initiates an increase of the three aforementioned amide bands and at the same time and a decrease with broadening of the N-H stretching vibration band at about $3200 \mathrm{~cm}^{-1}$ (Fig. 1, insets A1, A2). The stronger band at about $1700 \mathrm{~cm}^{-1}$ is explained on one hand by a stronger hydrogen bonding as stated above and on the other hand by associated carboxylic acids, which have strong bands around the same frequency regions (ca. 3200,1700 and $1200 \mathrm{~cm}^{-1}$; stretching vibration of $\mathrm{OH}, \mathrm{C}=\mathrm{O}$ and $\mathrm{C}-\mathrm{O}$ groups, respectively). ${ }^{45}$ Surprisingly, the amide II band becomes also more intensive, regardless the loss of urethane functionalities. This can be explained by an adjacent reaction between primary amines and carboxylic acids resulting in formation of secondary 
amides as it may occur under harsh conditions without catalysts or coupling agent. ${ }^{48,49}$ This hypothesis is supported by a subtle broadening of the amide I band on its right lower frequency slope (Fig. 1, inset $\mathrm{C} 1$ ) including contributions from secondary and primary amines (both absorb around $\left.165 \mathrm{~cm}^{-1}\right) .45$ Furthermore, the finding is explained by a non-linear behavior of $\mathrm{N}-\mathrm{H}$ and $-\mathrm{CH}_{2}-$ (methylene group) stretching vibration band intensities as a function of irradiation dose ( $\geq 50 \mathrm{kGy})$.

Similar to Aliph-TPU, also in Ar-TPU major noticeable changes in the material can be seen for the lowest investigated irradiation dose (25 kGy). Remarkable band intensity decreases of the methylene stretching vibration bands at 2920, $2850 \mathrm{~cm}^{-1}$ were found, referring to aliphatic chain scissions. A slight band intensity drop of $\mathrm{C}-\mathrm{O}-\mathrm{C}$ urethane or ester group at $1065 \mathrm{~cm}^{-1}$ was observed as well next to the aliphatic chains, whereas other methylene group bands (e.g. in the vicinity to adipate carbonyls, soft segment) remained almost constant. In addition, specific aromatic bands of the hard segment kept their intensity and profile or alter only marginally in comparison with other bands. This can be interpreted as a sign of chemical reactions starting at the "interface" hard- soft segments or within chain extender segments and in soft segments. Hence, contrarily to the aliphatic material, in Ar-TPU the linear aliphatic chain extenders in the hard segments as well as the aliphatic part of the soft segment seem to degrade both. However, taking a certain crystallinity (discussed in section 3.2) into account (signs of hydrogen bonding), means in conclusion that the soft segments are predominantly degraded. The amide bands of urethane increased in intensity, showing a probable formation of new-found groups (carboxylic acids, amides). With increasing of the irradiation dose ( $\geq 50 \mathrm{kGy}$ ) the amide I, II, III bands and N-H stretching vibration band have become either more intensive and slightly broader (around 1640 and $1230 \mathrm{~cm}^{-1}$ ) or change their intensity only negligibly. The intensity changes of methylene bands (at 2920, $285 \mathrm{o} \mathrm{cm}^{-1}$ ) has no definite correlation with irradiation dose, which is an indication of multiple chain scission and recombination involving new functional groups (carboxylic acids, amides). The total non-linear band dynamics and the changes in the amide bands are similar like in Aliph-TPU as discussed above.

From the findings by ATR-FTIR, we conclude that electron beam irradiation produces a cascade of similar parallel chemical reactions in the case of both TPUs including chain scission, chain recombination or branching as well as formation of new functionalities (amines, amides, carboxylic acids). The main irradiation response distinction between our systems is the location of the reaction/alternation onset. The hard segment (urethane functionality) undergoes chemical alternations first in the case of Aliph-TPU and the spectra of Ar-TPU show the chain extender of both soft and hard segment and soft segment degrade faster than hard segment core (urethane and aromatic groups), but in common in the case of TPUs it majorly depends on a formulation of a material. Earlier publications on aromatic TPUs, ${ }^{2,50}$ reported photo Fries rearrangement or oxidation of the central $-\mathrm{CH}_{2}-$ unit in the MDI segment. There is also an example for moderately irradiated aromatic TPU, where significant changes happened in soft segment. ${ }^{11}$ 


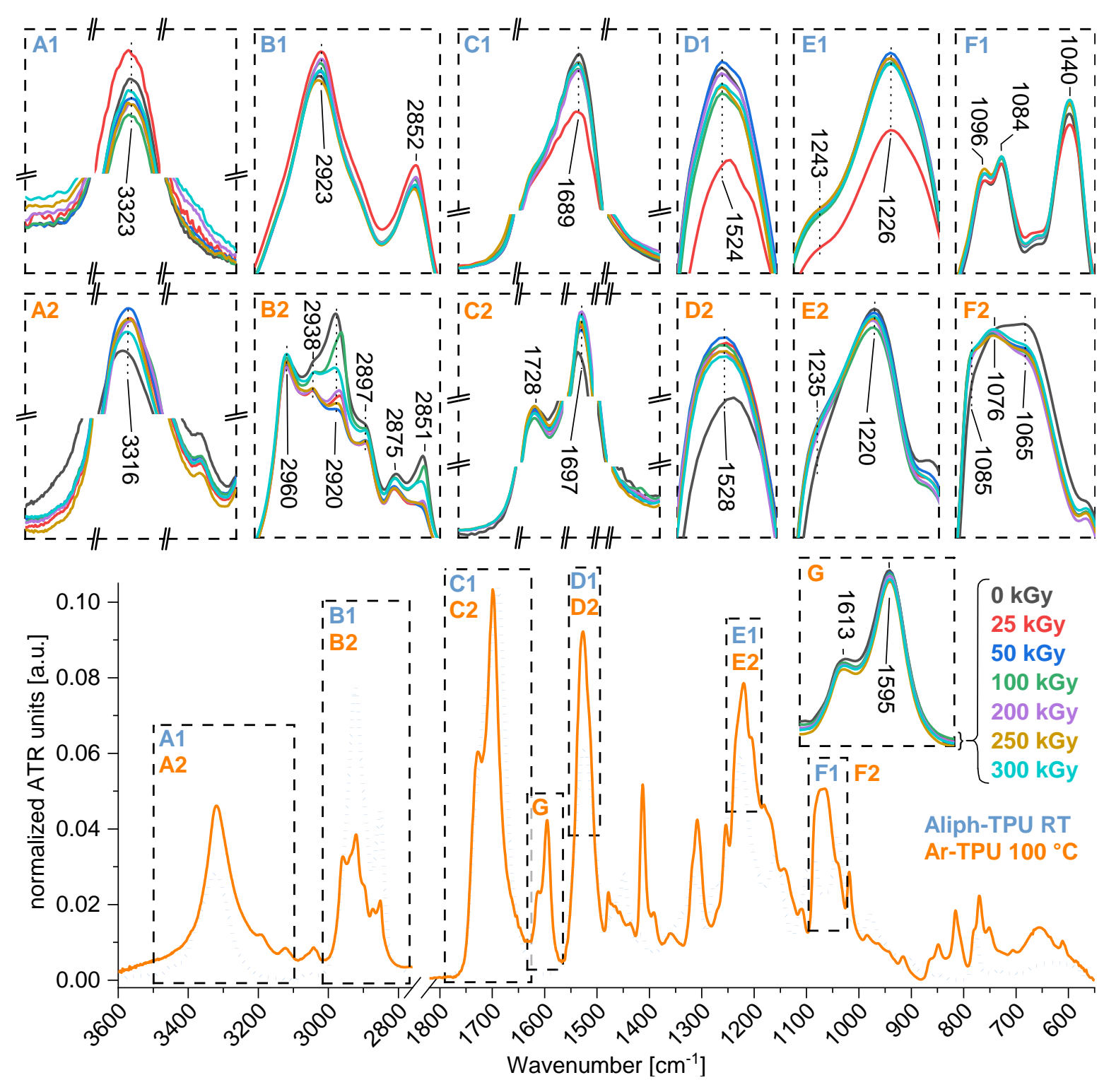

Figure 1 The vector-normalized ATR-FTIR spectra of the aliphatic (insets with no. 1) and the aromatic (insets with no. 2) TPU irradiated with different effective doses. The full spectra are presented for the non-irradiated materials, whereas the insets illustrate superimposed bands with significant changes. A1 and $\mathbf{B} 1$ show enlarged plots of the band region for $\mathrm{N}-\mathrm{H}$ stretching, A2 and $\mathbf{B} 3$ show the region of $\mathrm{C}-\mathrm{H}$ stretching. The insets $\mathbf{C} \mathbf{1}$ to E1 and $\mathbf{C 2}$ to E2 display the Amide I, II and III bands, respectively. F1 and F2 indicate the bands of $\mathrm{C}-\mathrm{O}-\mathrm{C}$ stretching vibrations. Solely for Ar-TPU, the aromatic ring vibration band in is shown in inset $\mathbf{G}$.

\subsection{DSC-Analysis}

Both TPU materials remained largely unaffected up to $270{ }^{\circ} \mathrm{C}$ as found by thermogravimetry ( $\mathrm{T}=$ $285{ }^{\circ} \mathrm{C}$ at $2 \%$ weight loss; see SI, Fig. S5), in spite a slight mass loss of ca. $0.5 \%$ was detected in the first full heating scan for both materials starting above $120{ }^{\circ} \mathrm{C}$ regardless of the irradiation, which caused a low and broad endothermic peak in the DSC endotherms (see Fig. S6, SI). This can be accounted to the loss of water entrapped in the material. 
The DSC analysis of Aliph-TPU showed in the first heating scan without pretreatment of the sample a relaxation peak superimposes the glass transition region. This phenomenon is well known for polymer glasses in general and originates from physical aging, e. g. by long storage of the material not far below the glass transition temperature..$^{52,53}$ Therefore the DSC analysis of Aliph-TPU was performed with a preheating step up to $80{ }^{\circ} \mathrm{C}$ prior the first full heating scan in order to drive out relaxation effects. With preheating, the endothermic peak was not observable anymore in following heating scans. Overall, no signs of melting or crystallization were found in the DSC thermograms, which indicates that Aliph-TPU is thoroughly amorphous.

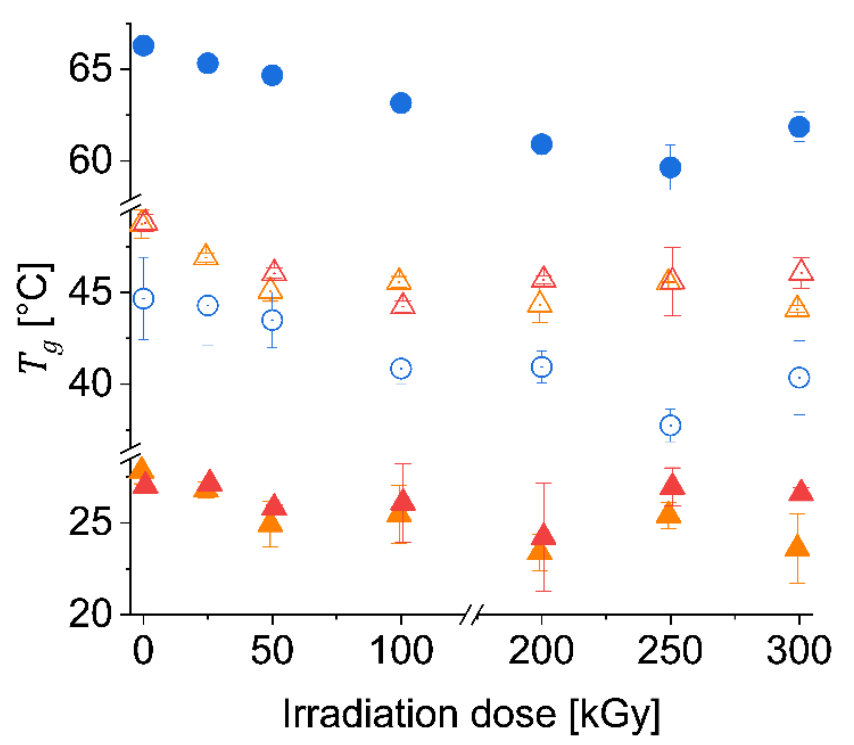

Figure 2 Glass transition temperatures $\left(T_{g}\right)$ of Aliph-TPU measured in the first heating scan (orange), in the cooling scan (blue) and in the second heating scan (red). Filled symbols display onset $T_{g}$ and open symbols show mid-point $T_{g}$ at half step height.

Therefore, a clear glass transition was observed at around $45{ }^{\circ} \mathrm{C}$ (half step height), which showed a slightly decreasing trend in its glass transition temperature $\left(T_{g}\right)$ in correlation to the irradiation dose from o kGy to $300 \mathrm{kGy}$ (see Fig. 2). Thereby the step height of glass transition $\Delta c_{p}$ does not show any significant trend, which indicates that the amorphous part of the material does not chance significantly under impact of irradiation (see Fig. S8 A, SI) The slight decrease in $T_{g}$ indicate isomerization or chain scission. ${ }^{54,55}$ Crosslinking can also not be excluded here, because degraded molecules of lower molar mass may also act as plasticizer in the material, which would also induce a decrease $T_{g}$, despite for crosslinking alone rather an increase in $T_{g}$ would be expected. ${ }^{56}$ 
A
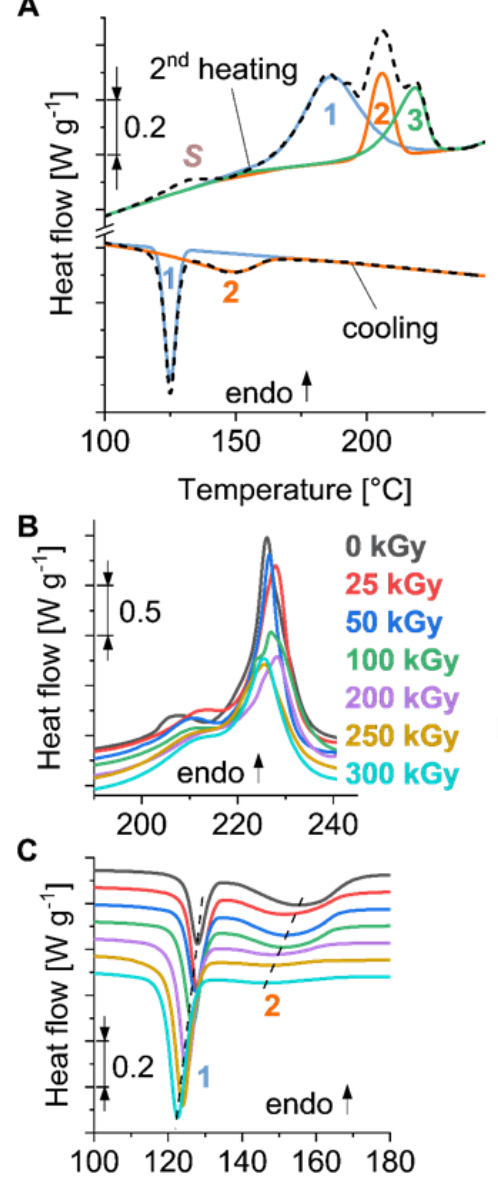

D

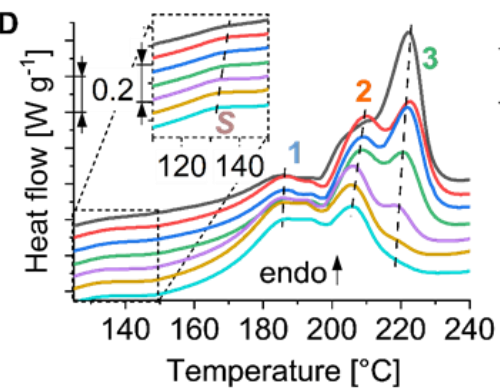

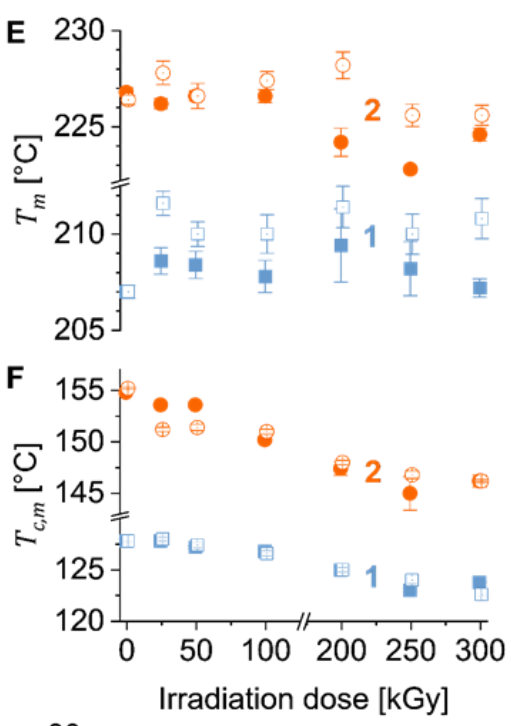
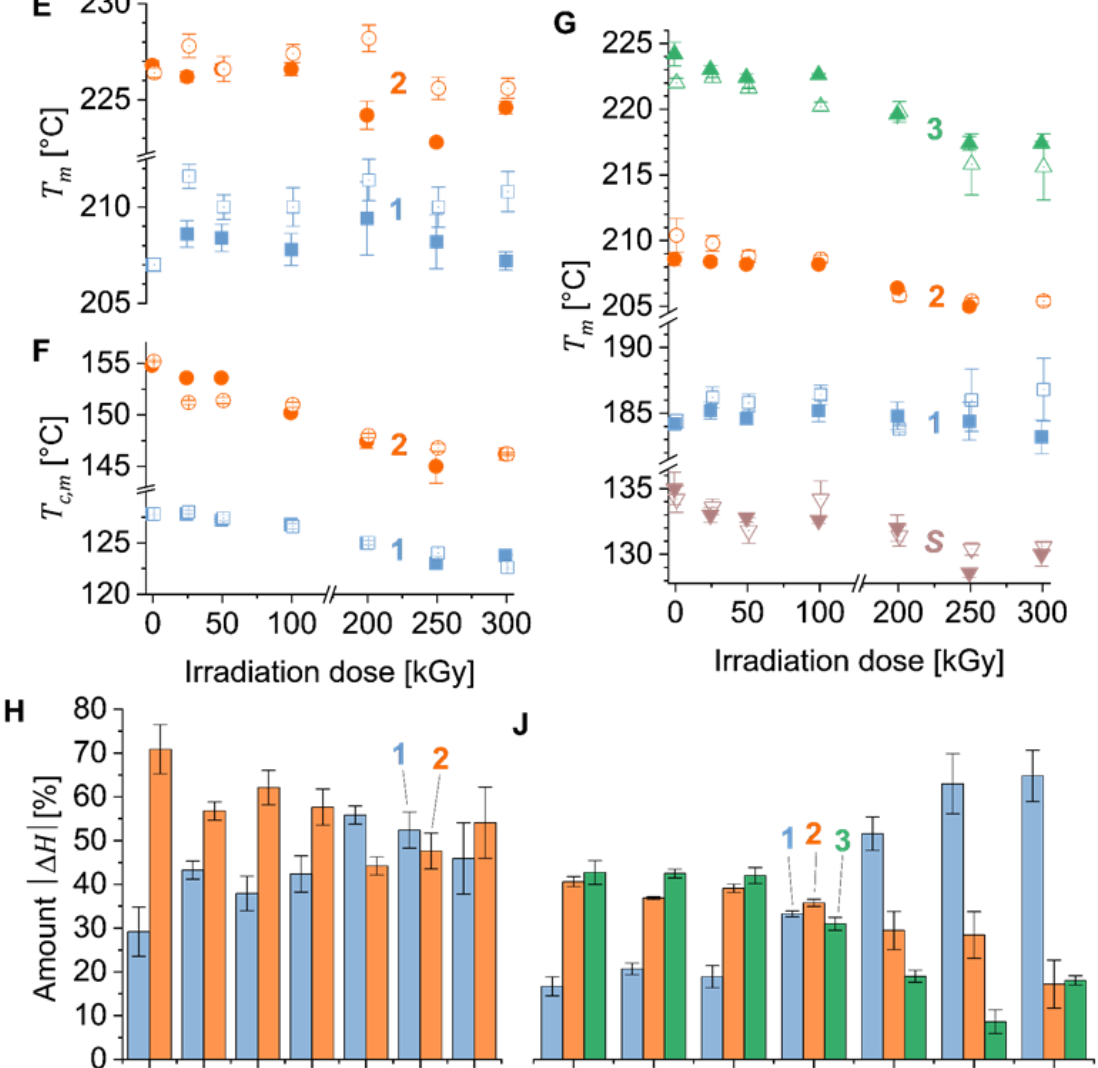

1

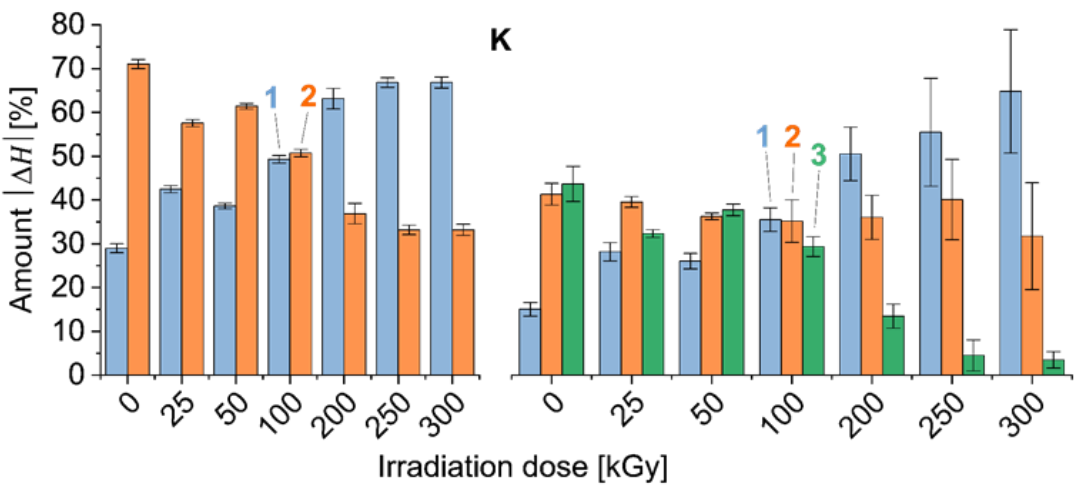

Figure 3 Melting and crystallization analysis of Ar-TPU by peak deconvolution (exemplarily shown in A) of DSC-thermograms shown here for the series irradiated at $100{ }^{\circ} \mathrm{C}$ in $\mathbf{B}$ with the melting peaks of the first heating, in $\mathbf{C}$ the crystallization peaks of the cooling scan and in $\mathbf{D}$ melting peaks of the second heating scan. The corresponding full thermograms for both series irradiated a RT and $100{ }^{\circ} \mathrm{C}$ are given in the Fig. S6, SI. The dashed lines in C and D are for guiding the eyes. The thermograms were shifted in $\mathrm{y}$-axis for better visibility. $\mathbf{E}$ indicates melting temperatures (all peak apexes) of the first heating and $\mathbf{G}$ of the second heating scan. $\mathbf{F}$ shows crystallization temperatures of the cooling scan. Hollow symbols in $\mathbf{E}$ to $\mathbf{G}$ represent the series irradiated at room temperature and filled symbols the series irradiated at $100{ }^{\circ} \mathrm{C}$. The relative amount of the melting and crystallization enthalpy is displayed from the deconvolution of the series irradiated at room temperature $(\mathbf{H}, \mathbf{J})$ and at $100{ }^{\circ} \mathrm{C}(\mathbf{I}, \mathbf{K})$ of the cooling $(\mathbf{H}, \mathbf{I})$ and the second heating scan (J, K). 
In contrast to Aliph-TPU, the DSC thermograms of the aromatic TPU showed in the first heating no and in the cooling as well as in the second heating only a weak and much broadened glass transition coming from the soft segments (see Fig. S7, SI). A slight increase in $T_{g}$ for both investigated irradiation temperatures was found, which is accounted to crosslinking. In contrast to Aliph-TPU, Ar-TPU showed distinct melting and crystallization peaks, respectively, identifying it as material with higher crystallinity. As illustrated in Figure 3 B to D, melting and crystallization show both an intrinsically complex multiple phase transition behavior with superimposed effects that are enhanced by irradiation. The first heating scan showed in general only one higher melting peak at about $226^{\circ} \mathrm{C}$ accompanied by one lower shoulder-like melting peak at about $207^{\circ} \mathrm{C}$. This corresponds somewhat to the bimodal crystallization peaks found in the cooling scans. However, the second heating scan indicated a multimodal melting behavior. The DSC heating scans were performed intentionally with a higher heating rate $\left(40 \mathrm{~K} \mathrm{~min}^{-1}\right)$. In previous studies reorganization and superheating effects during melting could be sufficiently suppressed. ${ }^{57,58}$ However, recent studies confirmed, that reorganization effects may still occur also at higher heating rates. ${ }^{59}$ Hence, we account this multimodal melting behavior in first instance as reorganization effects. The melting peak assigned with $\mathrm{S}$ at $130-135{ }^{\circ} \mathrm{C}$ in Fig. $3 \mathrm{D}$ possibly refers to a soft segment rich phase, whereas the following melting peak 1 at around $185^{\circ} \mathrm{C}$ may represent instead the melting of a mixed phase with higher hard segment content near the interface of the hard domains. The mixing of hard and soft segments at the interface of crystallites is reported to be originated in the dispersity of hard segments, which causes a fraction-wise crystallization according to segment length. ${ }^{60,61}$ Peak 2 is to be discussed as non-perfectly crystallized domains and peak 3 in consequence refers then to wellordered crystallites. Microphase mixing, also superimposed to the observed melting behavior, can be discussed as an origin of the observed reorganization effects. This was also reported in previous studies for TPU with high hard segment content. ${ }^{59,62}$ With increasing irradiation dose the amount of imperfect crystallites as well as assumedly mixed-phase crystallites increases tremendously. Meanwhile, the amount of well-ordered crystallites (Peak 3) with high hard segment content decreases (irradiation at RT) or almost disappears (irradiation at $100{ }^{\circ} \mathrm{C}$ ), respectively, as indicated in Figure $3 \mathrm{D}$ and confirmed by the enthalpy fractions from peak deconvolution (principle exemplarily shown in Fig. 3 A) of the multiple melting peaks (Fig. $3 \mathrm{~J}$ and $\mathrm{K}$ ). The trend to crystallites or domains of lower order was consistently found in in the thermograms of the cooling scan with an increasing amount of material crystallizing at lower temperature (Peak 1, see Fig. $3 \mathrm{H}$ and J). However, the reverse image of the multimodal phase transition (Fig. 3 D) was not observed in the cooling scans. Meanwhile, no significant differences in overall enthalpy was found between melting and cooling scans as well as with regard to irradiation dose (see Fig. S8 B, SI). This confirms on the one hand that no significant chemical transformations occurred in the DSC scans and on the other hand, that the multimodality found in the second heating is merged in the sharp crystallization peak, which can be explained by delayed crystallization far below the melting point(s) equilibrium due to absence of nuclei.

Next to the variation in fractions of melting and crystallization enthalpy stated above, all peaks, except in the first heating and peak 1 in the second heating showed decreasing trends in the (peak apex) melting temperatures $\left(T_{m}\right)$ and crystallization temperatures $\left(T_{c, m}\right)$, respectively, correlating with the irradiation dose (see Fig. 3 E, F, G). With the constancy in $T_{m}$, peak 1 can be discussed to represent a fraction in the outer part of domains interspersed with a significant content of soft segments. In that, 
the phase mixing and resulting crystallization seems not to be altered significantly by irradiation. Alternatively, changes could be hidden by other effects such as melting of different polymorphs in between lamellar and spherulite ${ }^{63,64}$ appearance and/or different discrete domain sizes, which possibly superimpose the observed overall melting behavior already intrinsically or induced by irradiation. However, the clarification of this matter exceeds the scope of this work and needs to be addressed in a future study.

Meanwhile, the temperature shifts and the shifts from well-ordered to increasingly disordered crystallites and domains indicate that irradiation induces isomerization, branching or topology changes, degradation of chains due to chain scission or, oppositely, crosslinking. Indications for chain scissions and possible recombination results in assumedly altered microstructure in agreement to the findings by ATR-FTIR.

With regard to the irradiation temperature, we found that the irradiation at elevated temperature leads to a greater shift from well-ordered crystallites to disorderly crystallizing domains than at room temperature, where a certain high melting fraction remains (Fig. $3 \mathrm{~J}$ and $\mathrm{K}$ ). Interestingly, the decrease in Peak 3 differing between the series at RT and $100{ }^{\circ} \mathrm{C}$ correlates only to the different increase of peak 2 , whereas the increase of peak 1 induced by irradiation is not significantly dependent on the temperature during irradiation. This supports the assumption, that peak 1 refers to a crystallite phase near the interface of the hard domain interfused with soft segments, which is not significantly affected by irradiation. In contrast to the enthalpy fractions, the melting and crystallization temperatures do not show significant differences in dependency to the irradiation temperature. The observed differences allow the conclusion, that the elevation of the irradiation temperature mainly increases the reaction rate of formed radicals leading to an increase in branching or crosslinking, but does not induce further changes e. $g$. in the chemical composition of the hard segments. In a recent study to electron beam irradiation of aromatic TPU chain scission or branching is reported to assumedly prevail over possible crosslinking reaction. ${ }^{6}$ However, for thorough understanding of the observed effects in the material investigated in this work with regard to irradiation dose and temperature a comprehensive, separation-based molar mass, size and conformation characterization is needed.

\subsection{Size exclusion chromatography}

Generally. when irradiation is applied to polymer material a vast number of different processes such as chain scission, ${ }^{66}$ crosslinking, ${ }^{67}$ branching, ${ }^{3,4}$ degradation, ${ }^{1,68,69}$ decomposition ${ }^{70}$ or chemical transformations ${ }^{66}$ e .g. oxidation ${ }^{71}$ must be taken into account. For TPU materials irradiated under inert conditions mainly chain scission, increase of branching and crosslinking need to be considered. ${ }^{2,51}$ Up to now, molar mass characterization of irradiated TPU is frequently carried out by SEC but mainly on the basis of relative calibration by polymer standards of narrow dispersity. ${ }^{16,65,72,73}$ However, particular fractions of branched polymers tend to elute not just according to their size, as it is expected for entropy mode elution. Fractions containing long chain branches may elute delayed as a consequence of anchoring effects of branches with the column packing material. ${ }^{19}$ Co-elution with less branched fractions of lower molar mass but of equal hydrodynamic size can result too. ${ }^{74,75}$ Therefore, the comparability of the analyzed polymer species to the used calibration standards and consequently the accuracy of the reported molar masses may be affected. An absolute molar mass determination by means of SEC coupled with 
MALS and dRI (differential refractive index) detection is therefore recommended and was already used in previous irradiation studies of PU material. ${ }^{18}$ In this study, we performed a comparison of different calculation methods. Molar mass calculation based on a calibration with polystyrene standards led clearly to erroneous molar mass moments in terms of number $\left(M_{n}\right)$ and weight average $\left(M_{w}\right)$ and an overestimation of the molar mass dispersity $\oslash=M_{w} M_{n}^{-1}$ (see Fig. S19, SI).

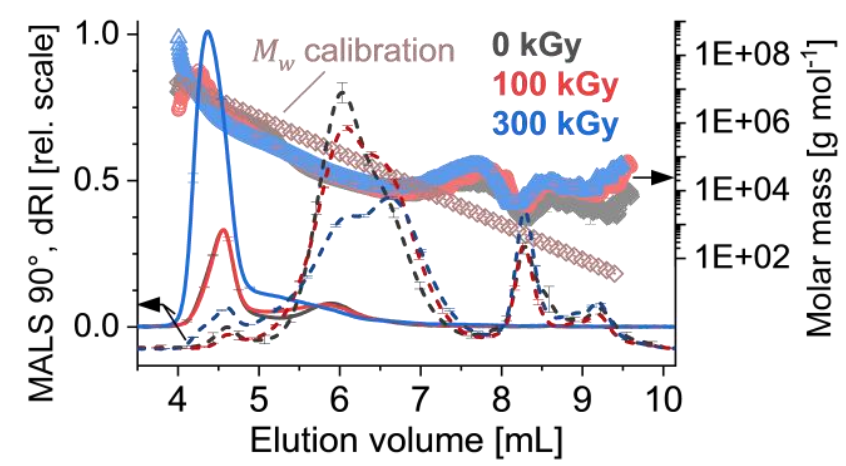

Figure 4 SEC-MALS-dRI chromatogram of the aliphatic TPU measured in $N, N$-dimethylacetamide $\left(+\mathrm{LiCl}, 3 \mathrm{~g} \mathrm{~L}^{-1}\right.$ ). The solid line indicates the MALS signal and the dashed line is the dRI response. The molar mass from calibration with narrow polystyrene standards is illustrated here for comparison.

SEC-MALS-dRI analyses of both TPU series showed a broad range in molar mass and size and with regard to the impacted irradiation dose a decrease of the main fraction accompanied by an increase of both, fractions of lower and higher molar masses (see Fig. 4 and Fig. S11, SI). Thereby a good resolution was achieved in the lower and medium molar mass range up to $10^{6} \mathrm{~g} \mathrm{~mol}^{-1}$, whereas in molar mass beyond that a separation performance is significantly reduced. The SEC-analysis revealed that already the untreated version (o kGy) of Aliph-TPU contains a certain fraction of higher molar mass, whereas for Ar-TPU this fraction shows very weak MALS response in an insignificantly low concentration. However, for both TPU series an abnormal elution behavior for both, the lower molar mass fraction as well as the ultra-high molar mass region (irradiated samples only) was observed, which also negatively affect the analysis of the polymer's conformation (see Fig S11 and S12, SI). Non-ideal elution behavior in SEC for hyperbranched PU material was also reported previously. ${ }^{76}$ This is one more reason that molar mass determination based on relative calibration for a non-purely entropy-based separation leads to false interpretation and therefore methods for an absolute molar mass and size determination are definitely required. Furthermore, ultra-high molar mass fraction exceeding significantly the separation range of SEC may also co-elute with smaller species of different topology due to an inversion of the separation mechanism from size exclusion to hydrodynamic chromatography mode..$^{77,78}$ 


\subsection{ThFFF analysis}

\subsection{1. $\quad$ Molar mass, size and weight fraction analysis}

To overcome the challenges in SEC a change of the separation mechanism to FFF with a much broader separation range may be a helpful alternative as it has been reported previously. ${ }^{19,79}$ Among the various FFF sub techniques, ThFFF may provide further information about intrinsic material properties such as differences in chemical composition ${ }^{19,25,29}$ (with changed solvent interaction) or differences in topology ${ }^{22-24,29}$ by the means of thermophoresis. ThFFF is a valuable complementary technique despite its separation range does not completely cover the range of SEC for low molar masses (see, Fig S19, SI).
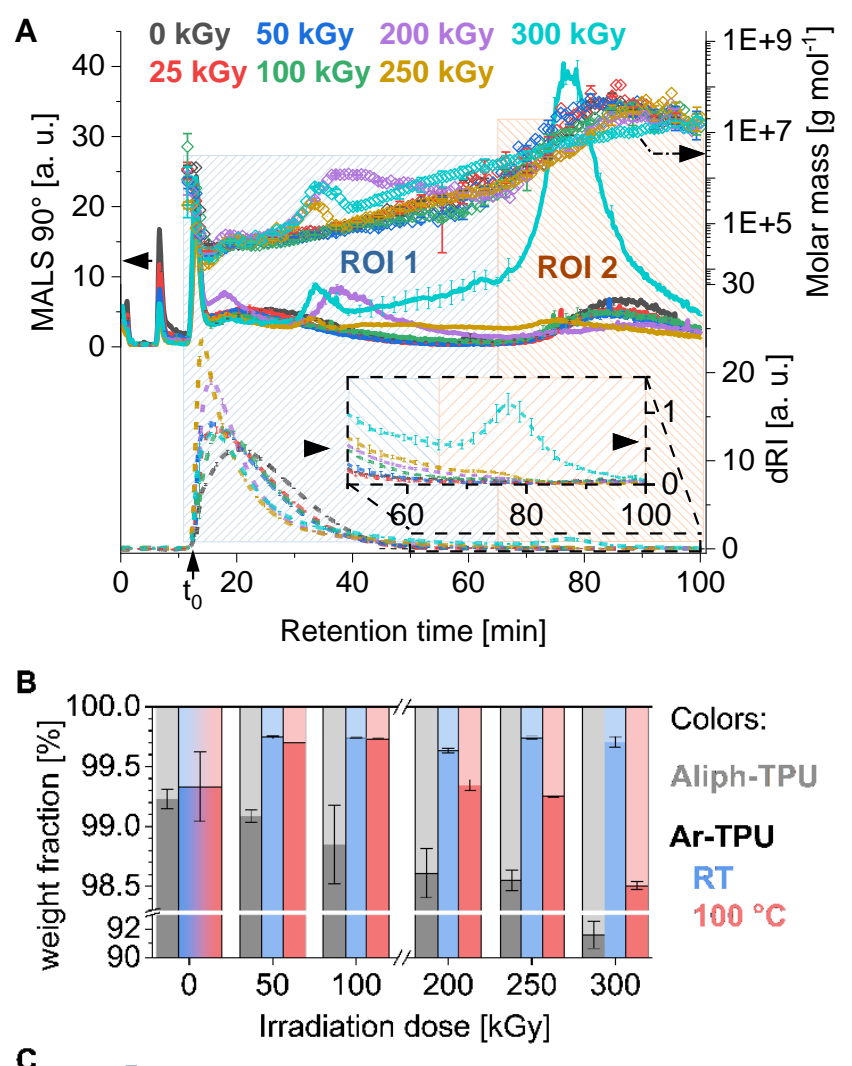

Colors:

Aliph-TPU

Ar-TPU

RT

$100^{\circ} \mathrm{C}$

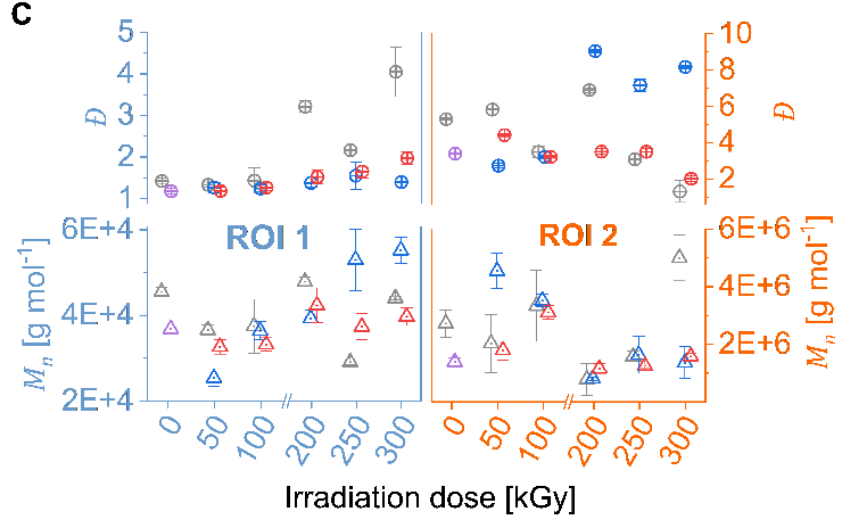

Figure 5 Fractogram after ThFFF separation of the aliphatic TPU (A). Weight fraction (B) and mean molar mass with dispersity (C) evaluation per region of interest of the aliphatic TPU (grey) irradiated at $\mathrm{RT}$ and the aromatic TPU irradiated at RT (blue) and at $100{ }^{\circ} \mathrm{C}$ (red). The stout colors in A refer to ROI 1 and the pale colors correspond to ROI 2 . 
In fact, the fractograms of the ThFFF (see Fig. $5 \mathrm{~A}$ ) indicate, that molar masses below $1 \mathrm{O}^{4} \mathrm{~g} \mathrm{~mol}^{-1}$ cannot be sufficiently resolved and elute together with the void peak at $t_{0}=12.36$ minutes. Included in this time is the stop flow time of $5 \mathrm{~min}$ being applied to reach an equilibrium relaxation of the analytes (further details see section 2.5, SI). Additionally, this fraction of unseparated analytes including also higher molar masses components may refer to densely compact objects with very low $S_{T}$. After the void peak, a good separation with high selectivity was observed. In order to keep the analysis time in a reasonable limit, a ThFFF method with a programmed temperature field had been optimized (see Fig. S4, SI) and two regions of interest (ROI) were defined: ROI 1 refers to poor and medium retained molecules in the retention region of about constant separation force field $\Delta T \approx 80 \mathrm{~K}$ and ROI 2 contains all further retained species where the separation was performed with a $\Delta T$ of programmed decay approaching $\Delta T \rightarrow$ o K.

The evaluation of the fractograms per ROI in Fig 5 B and C shows for both TPU materials in ROI2 first a slight decrease in weight fraction for low irradiation doses and thereafter an increase of the weight fraction containing ultra-high molar masses (UHMW) and possibly crosslinked species at high irradiation doses up to $300 \mathrm{kGy}$. For Aliph-TPU the increase of the weight fraction in ROI2 ranged from originally less than $1 \%$ up to $9 \%$ and is much higher than for Ar-TPU $100{ }^{\circ} \mathrm{C}$, for which ROI2 increased by only $1 \%$. In contrast, for Ar-TPU irradiated at RT the weight fraction in ROI 2 remained constantly low after first decrease at $50 \mathrm{kGy}$. Thus, the aliphatic TPU changes to a much greater extend under irradiation and forms a higher amount of crosslinked species. It can be concluded that for AliphTPU both, crosslinking and chain scission as competing mechanisms are reflected in $M_{n}$ and $\oslash$. In ROI 1 $Ð$ almost doubles, whereas $M_{n}$ fluctuated around a constant average. At the same time in ROI $2 M_{n}$ rises for all samples, but $Ð$ decreases here under intense irradiation. The reason for this is found in the molar mass differential distribution for the entire fractogram (see Fig. S15 A, SI). There, an increase of the UHMW fraction and a shift of the weight distribution towards lower molar masses is depicted, indicating an increasing probability for chain scission of UHMW species once a certain (very high) molar mass is reached by crosslinking. In contrast to Aliph-TPU, the aromatic TPU Ar-TPU does not show significant changes in $\oslash$ in ROI 1 when irradiated at RT, but an increase in $M_{n}$. Contrary, the irradiation at $100{ }^{\circ} \mathrm{C}$ leads to a slight increase in $\Theta$, but only to fluctuation in $M_{n}$. In ROI 2, both series (RT and $100{ }^{\circ} \mathrm{C}$ ) show a constant $M_{n}$, but for RT an increasing $\oslash$ and for $100{ }^{\circ} \mathrm{C}$ a decreasing $\oslash$ is observed. This can be also explained by the overall molar mass distribution (see Fig. S15 B and C, SI): During irradiation at room temperature crosslinked products with comparably lower molar masses are formed than at $100{ }^{\circ} \mathrm{C}$, where crosslinked products of higher molar masses are formed. The decreasing $\emptyset$ in ROI 2 for the $100{ }^{\circ} \mathrm{C}$ hints for increasing chain scission during irradiation by the raised irradiation temperature.

As found by DSC, the irradiation influences in both TPU materials to some extend the phase transitions, indicating next to molar mass de- or increase also topological changes such as increased branching. A suitable indicator for polymer topology is the scaling exponent $v_{R}$, obtained as the slope from linear fitting of the gyration radius (RMS) and molar mass from MALS, if the radii are larger than about $12 \mathrm{~nm}$ (depending on the signal to noise ratio), enabling interpretation of the angular dependency of the scattered light. ${ }^{80,81}$ This limits the applicability for this interpretation, since the main fraction for both TPU is below that limit. However, for the UHMW fraction conclusions about particle conformation 
may be drawn. In fact, the scaling exponents found by SEC-MALS-dRI for the first eluting fraction decrease from 0.62 (o kGy) to about 0.48 (see Table S1, SI). Typical scaling exponents are 0.59 for a random coil in a good solvent decreasing to 0.33 for a dense sphere. The scaling exponents found by ThFFF-MALS-dRI show the same trend from o.5 (Ar-TPU, o kGy) or slightly lower for Aliph-TPU down to about 0.3 indicating the formation of highly compact objects under irradiation (see Fig S16, SI) due to crosslinking and branching. The systematic difference of the scaling exponents between SEC and ThFFF is explained by differences in the solubility: For SEC the eluent $N, N$-dimethylacetamide was used with $\mathrm{LiCl}$ to enhance the solubility, disrupt possible intramolecular interactions like H-bonds and to decrease enthalpic interactions with the column material. In the ThFFF separations instead, the eluent had to be used without $\mathrm{LiCl}$ to avoid corrosion damage in the separation channel.

\subsubsection{Thermophoretic analysis}

Another indication for changes in topology, branching or changes in chemical composition is provided by the Soret coefficient $S_{T}{ }^{22-24}$ In this study changes in $S_{T}$ are mainly ascribed to changes in the polymer topology, because in ATR-FTIR no significant changes accounting for transformations in chemical composition were found, even though they are supposed to be more likely seen by ATR as stated in sect. 3.1.

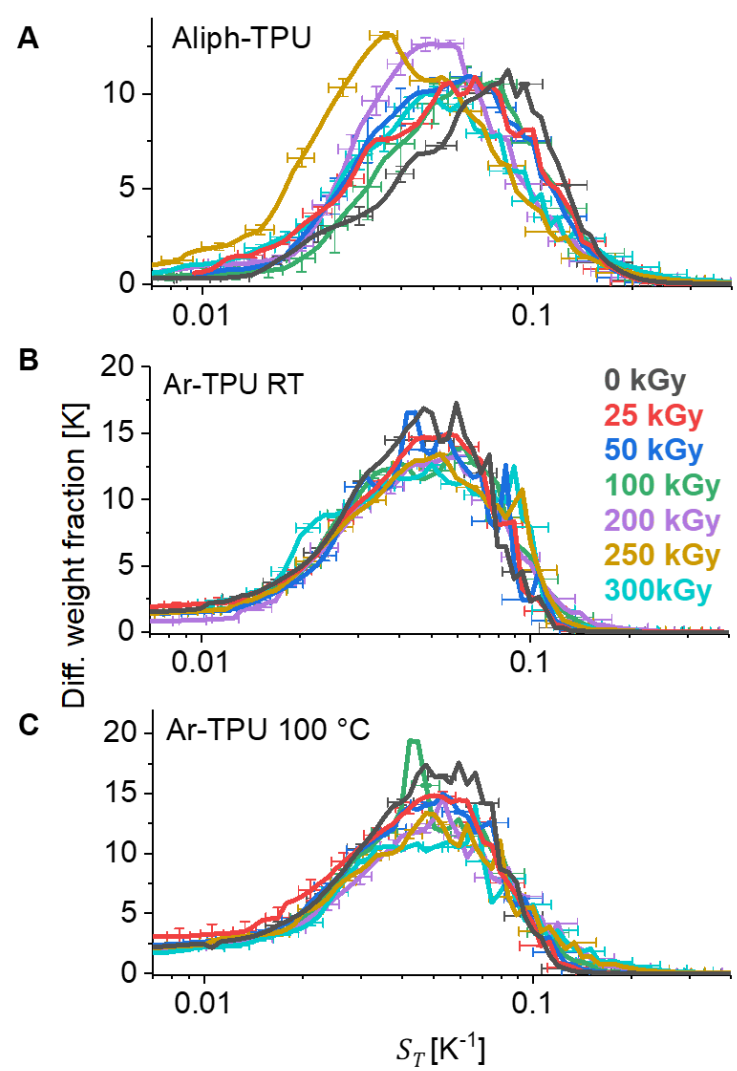

Figure 6 Differential weight distributions of $S_{T}$ calculated from the full ThFFF fractograms for AliphTPU (A), Ar-TPU irradiated at room temperature (B) and at $100{ }^{\circ} \mathrm{C}(\mathrm{C})$.

$S_{T}$ calculations per slice (per retention time) were performed with correction of the flow profile distortion $^{82}$ and with an adapted approach to correct secondary relaxation. ${ }^{83}$ Details are given in section 3.5.2 in the SI. The differential distributions of $S_{T}$ (see Fig 6) show a trend towards lower $S_{T}$ with irradiation 
for the aliphatic TPU indicating a shortening of linear segments in the polymer chains. ${ }^{23}$ At a first glance, both series of Ar-TPU do not show significant alterations neither due to irradiation dose nor due to the irradiation temperature. The difference to Aliph-TPU in $S_{T}$ as well as in the weight fraction analysis (see Fig. 5 B and C) allows concluding, that Ar-TPU is more resistant to irradiation, i.e. a higher energy is required to induce radical formation. This irradiation protection could originate from its crystalline nature.

A closer look at the cumulative $S_{T}$ distributions shows the influence of the irradiation temperature for Ar-TPU, allowing visualization of small differences over a broad distribution width, in contrast to differential distributions representation. On the other hand, differences in cumulative distributions in their steep region are not as easy to differentiate, which are better visible in the differential distribution plots. The number and weight average values commonly used for reporting polymer molar masses are similarly insensitive to display deviations in the distribution. Therefore, alternative characteristic mean values with higher sensitivity for in particular narrow distributions have been introduced. For our study we have adapted the concept of the cumulative distribution angle ${ }^{84}$ originally proposed for molar mass distributions to be used for the comparison of $S_{T}$ distributions. The distribution angle is expected to display changes in the steep region of the cumulative $S_{T}$ distribution. However, changes at the fronts and tails of the distribution may not be displayed by the distribution angle. Therefore additionally the width of the $S_{T}$ distribution $\Delta S_{T, D}$ taken from a comparable confidence interval is used in this study. The corresponding cumulative distributions are given in Fig. S18, SI.

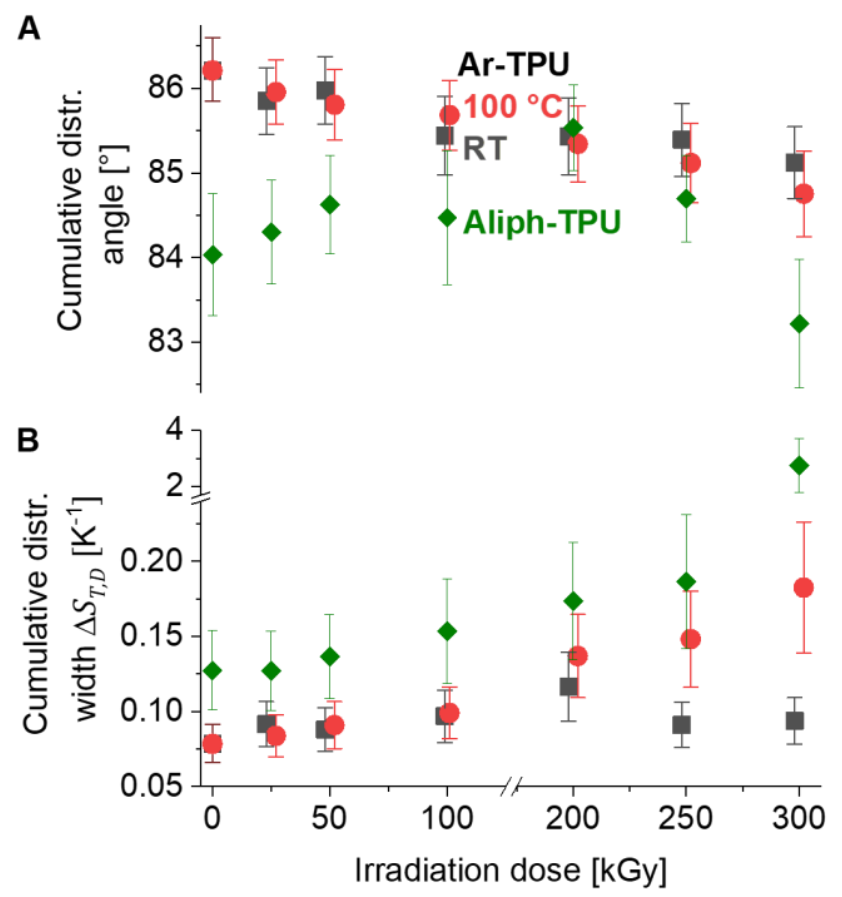

Figure 7 The cumulative distribution angle from linear fit of the cumulative distributions given in Fig. S18, SI in between the distribution interval (y-axis, relative scale) 0.15 until o.6 (A) and the distribution width $\Delta S_{T, D}(\mathbf{B})$ in between 0.05 until 0.95 of both TPU materials: Aliph-TPU irradiated at RT and ArTPU irradiated at RT and at $100{ }^{\circ} \mathrm{C}$. 
The analysis of the cumulative $S_{T}$ distributions shows, as illustrated in Fig. 18, for Aliph-TPU a slight increase in the distribution angle at low irradiation dose, followed by a decrease at higher irradiation doses. Meanwhile, $\Delta S_{T, D}$ shows only a steadily increasing width. This means, the main part of the $S_{T}$ distribution shifts to lower $S_{T}$, but does not significantly broaden, whereas significant broadening occurs at the front and the tail of the distribution, which indicates that under influence of the irradiation small fractions (mainly at the tail) with a comparably high $S_{T}$ are formed. Since crosslinking and branching have been found to be generated from irradiation, as discussed above, and causing a reduction in thermal diffusion, the increase in $S_{T}$ can be explained with formation of large particles up to the microscale, which possess $M_{w}$ in the UHMW range formed by crosslinking of already existing large macromolecular species.

The analysis for Ar-TPU shows different behavior for both irradiation temperature series: a constant decrease of the $S_{T}$ distribution angle combined with a slightly increasing $\Delta S_{T, D}$ at lower irradiation doses is observed. However, at higher irradiation a significant difference with regard to the irradiation temperature is found. Irradiation at elevated temperature leads to further increase of $\Delta S_{T, D}$ similar to Aliph-TPU. In contrast to this, $\Delta S_{T, D}$ stays almost constant when the irradiation is carried out at room temperature. This observation is in accordance to the differences found in the molar mass distributions (see Fig. S15, SI) and the different weight fractions found in ROI1, as stated in sect. 3.4.1., and supports the findings that crosslinking products of lower size and molar masses are formed at lower irradiation temperature, whereas additional architectures are formed at elevated temperatures in combination with higher irradiation dose. At these conditions an increase of chain scission combined with crosslinking is competing leading to broader molar mass range of the UHMW fraction for Ar-TPU $100{ }^{\circ} \mathrm{C}$ series. Consequently, the irradiation temperature changes the ratio between crosslinking and chain scission or degradation, while irradiation at lower temperature could suppress chain scission to some extent.

\section{Conclusions}

The influence of electron beam irradiation on commercially available aliphatic and aromatic thermoplastic polyurethane (TPU) material was thoroughly investigated on the molecular level by means of ATR-FTIR, DSC, SEC and complementary ThFFF separation, both separations coupled to absolute molar mass and size detection. Both materials are comparable in their hard and soft segment composition. ATR-FTIR investigations showed for both materials, that electron beam irradiation produces a cascade of parallel chemical reactions including chain scission and chain recombination leading to formation of branching, crosslinking as well as yield of new functionalities (amines, amides, carboxylic acids), which are recognizable already in significant amount at low irradiation doses. Thereby, in the aliphatic TPU signs of urethane group degradation and secondary amine formation revealed a predominant degradation of hard segments, whereas in the aromatic TPU the soft segments were found to degrade earlier as indicated by signs of isomerization in the polyol segments.

Accompanied studies by DSC unraveled the aliphatic TPU as thoroughly amorphous material with a distinct glass transition, in which the slight decrease of the glass transition temperature supports the findings from the ATR-FTIR study indicating isomerization or branching. The aromatic TPU showed instead a highly crystalline character with only a barely recognizable glass transition of its soft segments 
but a complex phase transition behavior with multiple melting and crystallization peaks. The multiple melting behavior caused by reorganization effects typical for TPU with high hard segment contents indicates an irradiation-induced transformation of the hard domains from well-ordered to increasingly disordered crystallites. The simultaneously found decreases in melting and crystallization temperatures furthermore support the conclusion of irradiation induced isomerization, branching or topology changes found by ATR-FT-IR and DSC. The irradiation influence on the aromatic TPU was studied at room temperature and at $100{ }^{\circ} \mathrm{C}$. The elevation of the irradiation temperature amplified the shift from wellordered crystallites to disorderly crystallizing domains, but showed no effects on the phase transition temperatures.

The molar mass and size characterizations revealed for both materials the formation of a highly crosslinked fraction with ultra-high molar masses, compact conformation and an increased dispersity as a result of the irradiation. This study addresses the challenges by the limits of SEC and possible deviations between SEC with absolute molar mass determination and calculations using relative calibration are demonstrated. Reliable determination of molar mass, size, and scaling with focus on the UHMW fraction was performed by ThFFF separation coupled to light scattering and dRI detection. Changes in topology were addressed by a thermophoretic analysis based on the ThFFF separation mechanism as a second independent investigation. These studies have revealed stronger tendency of the aliphatic TPU for crosslinking than the aromatic TPU, indicating a general high resistance of the aromatic TPU to irradiation. However, for the aliphatic TPU and for the aromatic TPU irradiated at $100{ }^{\circ} \mathrm{C}$ constant molar mass average in combination with a broadening in dispersity indicates that crosslinking is the main process competing with chain scission and degradation. For the aromatic TPU, lower irradiation temperature was found to significantly suppress chain scission and support crosslinking, although the crosslinking probability is also significantly reduced. Overall, this study unraveled, that crosslinking is the dominating effect under irradiation influence prevailing chain scission and degradation, which is in agreement to the literature for aliphatic ${ }^{7}$ and aromatic TPU. ${ }^{51}$

Future studies in this field may address inhomogeneous alterations in the material due to irradiation (surface to bulk) by diffuse deflection spectroscopy (IR, Raman) of the material in powdered state. Furthermore, the existence of different polymorphs or discrete domain sizes superimposing the observed reorganization effects in the overall melting behavior found by DSC was not elucidated further and will be examined in detail with regard to irradiation in a future study. ThFFF investigations using light scattering are accounted to give further insights into the scaling behavior with irradiated TPU material of higher molar mass or fractionation combined with online viscometry for an indirect access to radius information of the polymers below the detection limit of MALS. Modulated DSC may further resolve reorganization effects seen in the multiple melting and crystallization behavior of the aromatic TPU.

\section{Declaration of competing interest}

The authors declare that they have no known competing financial interests or personal relationships that could have appeared to influence the work reported in this manuscript. 


\section{ORCID}

Martin Geisler: 0000-0002-9414-0914

Brigitte Voit: 00oo-0002-4531-691X

Jürgen Pionteck: oooo-ooo3-2310-1106

Albena Lederer: 0ooo-0oo2-176o-6426

\section{Authorship contribution statement}

Martin Geisler: investigation, conceptualization, validation, writing - original draft, writing - review \& editing, visualization. Tuhin Subhra Pal: investigation, formal analysis. Kerstin Arnhold: thermal analysis investigation and evaluation, writing - review \& editing. Mikhail Malanin: ATR-FT-IR investigation and evaluation, writing - review \& editing. Michael Thomas Müller: sample preparation, writing - review \& editing. Brigitte Voit: supervision, resources, writing - review \& editing. Jürgen Pionteck: conceptualization, validation, supervision, writing - review \& editing. Albena Lederer: validation, supervision, writing - review \& editing. All authors have given approval to the final version of the manuscript.

\section{Acknowledgements}

This work was supported by the German Academic Exchange Service (DAAD) and the Ministry of Human Resource Development India. Hartmut Komber from IPF Dresden is greatly acknowledged for the NMR investigations of the materials. We thank Christina Harnisch from IPF Dresden for technical assistance in the SEC analysis. Lothar Jakisch is acknowledged for guidance in the ATR-FIR analysis and Sabine Krause (both from IPF Dresden) for help in thermal analyses. We thank Mr. Nikhil Kumar Singha, Prasanta Kumar Behera (IIT Kharagpur) and Susanne Boye (IPF Dresden) for valuable discussions regarding the interpretation of the results.

\section{Appendix A. Supporting Information}

Theroretical background on ThFFF, $S_{T}$ distribution angle and $\Delta S_{T, D}$, experimental details, additional results to DSC, NMR, SEC and THFFF with correction of secondary relaxation for thermophoretic analysis, comparison of molar mass distributions between calibrated SEC, SEC-MALS and ThFFF-MALS (PDF).

\section{References}

(1) Yousif, E.; Haddad, R. Photodegradation and Photostabilization of Polymers, Especially Polystyrene: Review. Springerplus 2013, 2 (1), 398. doi: 10.1186/2193-1801-2-398.

(2) Wilhelm, C.; Rivaton, A.; Gardette, J. L. Infrared Analysis of the Photochemical Behaviour of Segmented Polyurethanes: 3. Aromatic Diisocyanate Based Polymers. Polymer 1998, 39 (5), 1223-1232. doi: 10.1016/Soo32-3861(97)0o353-4.

(3) Krause, B.; Voigt, D.; Häußler, L.; Auhl, D.; Münstedt, H. Characterization of Electron Beam Irradiated Polypropylene: Influence of Irradiation Temperature on Molecular and Rheological Properties. J. Appl. Polym. Sci. 2006, 100 (4), 2770-2780. doi: 10.1002/app.23453. 
(4) Krause, B.; Voigt, D.; Lederer, A.; Auhl, D.; Münstedt, H. Determination of Low Amounts of Long-Chain Branches in Polypropylene Using a Combination of Chromatographic and Rheological Methods. J. Chromatogr. A 2004, 1056 (1-2), 217-222. doi: 10.1016/J.CHROMA.2004.06.127.

(5) Szycher, M. Basic Concepts in Polyurethane Chemistry and Technology. In Szychers Handbook of Polyurethanes, Second Edition; 2012; pp 13-36. doi: 10.1201/b12343.

(6) Thomson, T. Polyurethane Chemistry. In Polyurethane Immobilization of Cells and Biomolecules; Wiley Online Books; 2017; pp 1-27. doi: 10.1002/9781119264958.ch1.

(7) Adem, E.; Angulo-Cervera, E.; González-Jiménez, A.; Valentín, J. L.; Marcos-Fernández, A. Effect of Dose and Temperature on the Physical Properties of an Aliphatic Thermoplastic Polyurethane Irradiated with an Electron Beam. Radiat. Phys. Chem. 2015, 112, 61-70. doi: 10.1016/j.radphyschem.2015.03.017.

(8) Wilhelm, C.; Gardette, J. L. Infrared Analysis of the Photochemical Behaviour of Segmented Polyurethanes: Aliphatic Poly(Ether-Urethane)S. Polymer 1998, 39 (24), 5973-5980. doi: 10.1016/Soo32-3861(97)10065-9.

(9) Sui, H.; Ju, X.; Liu, X.; Cheng, K.; Luo, Y.; Zhong, F. Primary Thermal Degradation Effects on the Polyurethane Film. Polym. Degrad. Stab. 2014, 101 (1), 109-113. doi: 10.1016/j.polymdegradstab.2013.11.021.

(10) Sui, H. L.; Liu, X. Y.; Zhong, F. C.; Li, X. Y.; Ju, X. A Study of Radiation Effects on Polyester Urethane Using Two-Dimensional Correlation Analysis Based on Thermogravimetric Data. Polym. Degrad. Stab. 2013, 98 (1), 255-26o. doi: 10.1016/j.polymdegradstab.2012.10.003.

(11) Ghobashy, M. M.; Abdeen, Z. I. Radiation Crosslinking of Polyurethanes: Characterization by FTIR, TGA, SEM, XRD, and Raman Spectroscopy. J. Polym. 2016, 2016, 1-9. doi: $10.1155 / 2016 / 9802514$.

(12) Dong, F.; Maganty, S.; Meschter, S. J.; Nozaki, S.; Ohshima, T.; Makino, T.; Cho, J. Electron Beam Irradiation Effect on the Mechanical Properties of Nanosilica-Filled Polyurethane Films. Polym. Degrad. Stab. 2017, 141, 45-53. doi: 10.1016/j.polymdegradstab.2017.05.003.

(13) Dutta, J.; Chatterjee, T.; Dhara, G.; Naskar, K. Exploring the Influence of Electron Beam Irradiation on the Morphology, Physico-Mechanical, Thermal Behaviour and Performance Properties of EVA and TPU Blends. RSC Adv. 2015, 5 (52), 41563-41575. doi: 10.1039/c5rao3381k.

(14) Ravat, B.; Grivet, M.; Grohens, Y.; Chambaudet, A. Electron Irradiation of Polyesterurethane: Study of Chemical and Structural Modifications Using FTIR, UV Spectroscopy and GPC. Radiat. Meas. 2001, 34 (1-6), 31-36. doi: 10.1016/S1350-4487(01)oo116-o.

(15) Ravat, B.; Oudot, B.; Grivet, M.; Grohens, Y.; Chambaudet, A. Electron Irradiation of Polyurethane Using UV Spectroscopy, GPC and Swelling Analyses. Radiat. Phys. Chem. 2oo2, 63 (1), 93-99. doi: 10.1016/Sog69-806X(01)oo488-1.

(16) Tian, Q.; Takács, E.; Krakovský, I.; Horváth, Z. E.; Rosta, L.; Almásy, L. Study on the Microstructure of Polyester Polyurethane Irradiated in Air and Water. Polymers 2015, 7 (9), 1755-1766. doi: 10.3390/polym7091481.

(17) Deng, Y. W.; Yu, T. L.; Ho, C. H. Effect of Aging under Strain on the Physical Properties of Polyester-Urethane Elastomer. Polym. J. 1994, 26 (12), 1368-1376. doi: 10.1295/polymj.26.1368.

(18) Cooke, S. L.; Whittington, A. R. Investigation into Polyurethane at Varying Dose Rates of Ionizing Radiation for Clinical Application. J. Chem. 2018, 2018, 7312147. doi: 10.1155/2018/7312147. 
(19) Podzimek, S.; Vlcek, T.; Johann, C. Characterization of Branched Polymers by Size Exclusion Chromatography Coupled with Multiangle Light Scattering Detector. I. Size Exclusion Chromatography Elution Behavior of Branched Polymers. J. Appl. Polym. Sci. 2001, 81 (7), 15881594. doi: 10.1002/app.1589.

(20) Brandt, J.; Lenz, J.; Pahnke, K.; Schmidt, F. G.; Barner-Kowollik, C.; Lederer, A. Investigation of Thermoreversible Polymer Networks by Temperature Dependent Size Exclusion Chromatography. Polym. Chem. 2017, 8 (43), 6598-6605. doi: 10.1039/c7pyo1262d.

(21) Schimpf, M. E.; Caldwell, K.; Giddings, J. C. Field-Flow Fractionation Handbook; John Wiley \& Sons, Inc.: New York, USA, 2000, pp. 31-38 and pp. 103-132.

(22) Smith, W. C.; Geisler, M.; Lederer, A.; Williams, S. K. R. Thermal Field-Flow Fractionation for Characterization of Architecture in Hyperbranched Aromatic-Aliphatic Polyesters with Controlled Branching. Anal. Chem. 2019, 91 (19), 12344-12351. doi: 10.1021/acs.analchem.9bo2664.

(23) Geisler, M.; Smith, W. C.; Plüschke, L.; Mundil, R.; Merna, J.; Williams, S. K. R.; Lederer, A. Topology Analysis of Chain Walking Polymerized Polyethylene: An Alternative Approach for the Branching Characterization by Thermal FFF. Macromolecules 2019, 52 (22), 8662-8671. doi: 10.1021/acs.macromol.gbo1410.

(24) Greyling, G.; Lederer, A.; Pasch, H. Thermal Field-Flow Fractionation for the Investigation of the Thermoresponsive Nature of Star and Linear Polystyrene. Macromol. Chem. Phys. 2018, 219 (24), 1800417. doi: 10.1002/macp.201800417.

(25) Schimpf, M. E.; Wheeler, L. M.; Romeo, P. F. Copolymer Retention in Thermal Field-Flow Fractionation. In Chromatography of Polymers; ACS Symposium Series; American Chemical Society, 1993; Vol. 521, pp 63-76. doi: 10.1021/bk-1993-0521.choo5.

(26) Ponyik, C. A.; Wu, D. T.; Williams, S. K. R. Separation and Composition Distribution Determination of Triblock Copolymers by Thermal Field-Flow Fractionation. Anal. Bioanal. Chem. 2013, 405 (28), 9033-9040. doi: 10.1007/s00216-013-7282-6.

(27) Schimpf, M. E.; Giddings, J. C. Characterization of Thermal Diffusion of Copolymers in Solution by Thermal Field-flow Fractionation. J. Polym. Sci. Part B Polym. Phys. 1990, 28 (13), 26732680. doi: 10.1002/polb.1990.090281313.

(28) Mes, E. P. C.; Tijssen, R.; Kok, W. T. Rapid Detection of Compositional Drift of Polydisperse Copolymers Using Thermal Field-Flow Fractionation and Multi-Angle Light Scattering. Chromatographia 1999, 50 (1-2), 45-51. doi: 10.1007/BFo2493616.

(29) Runyon, J. R.; Williams, S. K. R. Composition and Molecular Weight Analysis of Styrene-Acrylic Copolymers Using Thermal Field-Flow Fractionation. J. Chromatogr. A 2011, 1218 (38), 67746779. doi: 10.1016/j.chroma.2011.07.076.

(30) Greyling, G.; Pasch, H. Thermal Field-Flow Fractionation (ThFFF); Greyling, G., Pasch, H., Eds.; Springer International Publishing: Cham, 2019; pp 13-29. doi: 10.1007/978-3-030-10650-8_2.

(31) Muza, U. L.; Greyling, G.; Pasch, H. Stereocomplexation of Polymers in Micelle Nanoreactors As Studied by Multiple Detection Thermal Field-Flow Fractionation. Anal. Chem. 2018, 90 (23), 13987-13995. doi: 10.1021/acs.analchem.8bo359o.

(32) Muza, U. L.; Pasch, H. Thermal Field-Flow Fractionation with Quintuple Detection for the Comprehensive Analysis of Complex Polymers. Anal. Chem. 2019, 91 (10), 6926-6933. doi: 10.1021/acs.analchem.9bo1384. 
（33） Radebe, N. W.; Beskers, T.; Greyling, G.; Pasch, H. Online Coupling of Thermal Field-Flow Fractionation and Fourier Transform Infrared Spectroscopy as a Powerful Tool for Polymer Characterization. J. Chromatogr. A 2019, 1587, 180-188. doi: 10.1016/J.CHROMA.2018.12.012.

(34) Greyling, G.; Pasch, H. Characterisation of Block Copolymer Self-Assemblies by Thermal FieldFlow Fractionation. Polym. Int. 2017, 66 (6), 745-751. doi: 10.1002/pi.5350.

(35) Greyling, G.; Pasch, H. Multidetector Thermal Field-Flow Fractionation: A Unique Tool for Monitoring the Structure and Dynamics of Block Copolymer Micelles. Macromolecules 2016, 49 (5), 1882-1889. doi: 10.1021/acs.macromol.5bo2634.

(36) Soret, C. Sur l'état d'équilibre Que Prend, Au Point de Vue de Sa Concentration, Une Dissolution Saline Primitivement Homogène, Dont Deux Parties Sont Portées à Des Températures Différentes. J. Phys. Theor. Appl. 1880, 9 (1), 331-332.

(37) Ludwig, C. Diffusion Zwischen Ungleich Erwärmten Orten Gleich Zusammengesetzter Lösungen. Sitzungber. Bayer. Akad. Wiss. Wien Math.-Naturwiss. Kl. 1856, 20, 539.

(38) Mes, E. P. C.; Kok, W. T.; Tijssen, R. Prediction of Polymer Thermal Diffusion Coefficients from Polymer-Solvent Interaction Parameters: Comparison with Thermal Field Flow Fractionation and Thermal Diffusion Forced Rayleigh Scattering Experiments. Int. J. Polym. Anal. Charact. 2003, 8 (2), 133-153. doi: 10.1080/10236660304888.

（39） Runyon, J. R.; Williams, S. K. R. A Theory-Based Approach to Thermal Field-Flow Fractionation of Polyacrylates. J. Chromatogr. A 2011, 1218 (39), 7016-7022. doi: 10.1016/J.CHROMA.2011.08.007.

(40) Stadelmaier, D.; Köhler, W. Thermal Diffusion of Dilute Polymer Solutions: The Role of Chain Flexibility and the Effective Segment Size. Macromolecules 2009, 42 (22), 9147-9152. doi: 10.1021/mag01794k.

(41) Einstein, A. Eine Neue Bestimmung Der Moleküldimensionen. Ann. Phys. 19o6, 324 (2), 289306. doi: 10.1002/andp.19063240204.

(42) Fischer, W. B.; Pötschke, P.; Pompe, G.; Eichhorn, K. J.; Siesler, H. W. Rheo-Optical Fourier Transform Infrared Spectroscopy of Polyurethanes and Their Blends with Polyolefins. Macromol. Chem. Phys. 1997, 198 (7), 2057-2072. doi: 10.1002/macp.1997.021980705.

(43) Hiltz, J.; Szabo, J. FT-IR Study of Poly(Ether)Urethanes; Technical memorandum, 2001, 2001073, Defense Research Establishment Atlantic, Canada. doi: 10.13140/2.1.1378.3843.

(44) Suchkova, G. G.; Maklakov, L. I. Amide Bands in the IR Spectra of Urethanes. Vib. Spectrosc. 2009, 51 (2), 333-339. doi: 10.1016/j.vibspec.2009.09.002.

(45) Socrates, G. Infrared and Raman Characteristic Group Frequencies: Tables and Charts; John Wiley \& Sons, 2004.

(46) Hummel, D. O.; Scholl, F. Atlas of Polymer and Plastics Analysis; Atlas of Polymer and Plastics Analysis; Verlag Chemie International: Munich, 1978, p. 387.

(47) Coleman, M. M.; Skrovanek, D. J.; Hu, J.; Painter, P. C. Hydrogen Bonding in Polymer Blends. 1. FTIR Studies of Urethane-Ether Blends. Macromolecules 1988, 21 (1), 59-65. doi: 10.1021/maoo179ao14.

(48) Jursic, B. S.; Zdravkovski, Z. A Simple Preparation of Amides from Acids and Amines by Heating of Their Mixture. Synth. Commun. 1993, 23 (19), 2761-2770. doi: 10.1080/o0397919308013807.

(49) Cossy, J.; Pale-Grosdemange, C. A Convenient Synthesis of Amides from Carboxylic Acids and Primary Amines. Tetrahedron Lett. 1989, 30 (21), 2771-2774.

doi: 10.1016/Soo40-4039(0o)99121-4. 
(50) Mrad, O.; Saunier, J.; Aymes Chodur, C.; Rosilio, V.; Agnely, F.; Aubert, P.; Vigneron, J.; Etcheberry, A.; Yagoubi, N. A Comparison of Plasma and Electron Beam-Sterilization of PU Catheters. Radiat. Phys. Chem. 2010, 79 (1), 93-103. doi: 10.1016/j.radphyschem.2009.08.038.

(51) Murray, K. A.; Kennedy, J. E.; McEvoy, B.; Vrain, O.; Ryan, D.; Cowman, R.; Higginbotham, C. L. The Influence of Electron Beam Irradiation Conducted in Air on the Thermal, Chemical, Structural and Surface Properties of Medical Grade Polyurethane. Eur. Polym. J. 2013, 49 (7), 1782-1795. doi: 10.1016/j.eurpolymj.2013.03.034.

(52) Hodge, I. M. Physical Aging in Polymer Glasses. Science 1995, 267 (5206), 1945-1947. doi: 10.1126/science.267.5206.1945.

(53) Struik, L. C. E. Physical Aging in Amorphous Polymers and Other Materials, 2nd ed.; Elsevier Scientific Publishing Company: Amsterdam, 1978, pp. 97-122.

(54) Wunderlich, B. Single Component Materials. In Thermal Analysis of Polymeric Materials; Wunderlich, B., Ed.; Springer Berlin Heidelberg: Berlin, Heidelberg, 2005; pp 591-704. doi: 10.1007/3-540-26360-8_6.

(55) Seyler, R. J. Assignment of the Glass Transition; Astm International, 1994; Vol. 1249. doi: 10.1520/stp1249-eb.

(56) Sharaf, M. A.; Mark, J. E. Effects of Cross-Linking and Strain on the Glass Transition Temperature of a Polymer Network. Rubber Chem. Technol. 1980, 53 (4), 982-987. doi: 10.5254/1.3535073.

(57) Koberstein, J. T.; Galembos, A. F.; Leung, L. M. Compression-Molded Polyurethane Block Copolymers. 1. Microdomain Morphology and Thermomechanical Properties. Macromolecules 1992, 25 (23), 6195-6204. doi: 10.1021/maooo49a017.

(58) Koberstein, J. T.; Galembos, A. F. Multiple Melting in Segmented Polyurethane Block Copolymers. Macromolecules 1992, 25 (21), 5618-5624. doi: 10.1021/maooo47a010.

（59） Balko, J.; Fernández-D’Arlas, B.; Pöselt, E.; Dabbous, R.; Müller, A. J.; Thurn-Albrecht, T. Clarifying the Origin of Multiple Melting of Segmented Thermoplastic Polyurethanes by Fast Scanning Calorimetry. Macromolecules 2017, 50 (19), 7672-7680. doi: 10.1021/acs.macromol.7boo871.

(6o) Koberstein, J. T.; Stein, R. S. Small-Angle X-Ray Scattering Studies of Microdomain Structure in Segmented Polyurethane Elastomers. J. Polym. Sci. Part A-2, Polym. Phys. 1983, 21 (8), 14391472. doi: 10.1002/pol.1983.180210814.

(61) Koberstein, J. T.; Stein, R. S. Small-Angle X-Ray Scattering Measurements of Diffuse PhaseBoundary Thicknesses in Segmented Polyurethane Elastomers. J. Polym. Sci. Part A-2, Polym. Phys. 1983, 21 (10), 2181-2200. doi: 10.1002/pol.1983.180211025.

(62) Saiani, A.; Daunch, W. A.; Verbeke, H.; Leenslag, J. W.; Higgins, J. S. Origin of Multiple Melting Endotherms in a High Hard Block Content Polyurethane. 1. Thermodynamic Investigation. Macromolecules 2001, 34 (26), 9059-9068. doi: 10.1021/ma0105993.

(63) Mishra, A.; Maiti, P. Morphology of Polyurethanes at Various Length Scale: The Influence of Chain Structure. J. Appl. Polym. Sci. 2011, 120 (6), 3546-3555. doi: 10.1002/app.33525.

(64) Fridman, I. D.; Thomas, E. L. Morphology of Crystalline Polyurethane Hard Segment Domains and Spherulites. Polymer 1980, 21 (4), 388-392. doi: 10.1016/o032-3861(80)900o7-5.

(65) Navarro, R.; Rubio Hernández-Sampelayo, A.; Adem, E.; Marcos-Fernández, A. Effect of Electron Beam Irradiation on the Properties of Poly(Tetramethylene Oxide) and a Poly(Tetramethylene Oxide)-Based Polyurethane. Radiat. Phys. Chem. 2020, 174, 108905. doi: 10.1016/j.radphyschem.2020.108905. 
(66) Chapiro, A. Chemical Modifications in Irradiated Polymers. Nucl. Inst. Methods Phys. Res. B 1988, 32 (1-4), 111-114. doi: 10.1016/0168-583X(88)90191-7.

(67) Kltamaru, R.; Mandelkern, L. Irradiation Cross Linking of Polyethylene. The Temperature Dependence of Cross Linking in the Crystalline and Amorphous States. J. Am. Chem. Soc. 1964, 86 (17), 3529-3534. doi: 10.1021/jao1071ao27.

(68) Guignot, C.; Betz, N.; Legendre, B.; Le Moel, A.; Yagoubi, N. Degradation of Segmented Poly(Etherurethane) Tecoflex ${ }^{\circledR}$ Induced by Electron Beam Irradiation: Characterization and Evaluation. Nucl. Instruments Methods Phys. Res. Sect. B Beam Interact. with Mater. Atoms 2001, 185 (1-4), 100-107. doi: 10.1016/So168-583X(01)00850-3.

(69) Dannoux, A.; Esnouf, S.; Begue, J.; Amekraz, B.; Moulin, C. Degradation Kinetics of Poly(EtherUrethane) Estane ${ }^{\circledR}$ Induced by Electron Irradiation. Nucl. Instruments Methods Phys. Res. Sect. B Beam Interact. with Mater. Atoms 2005, 236 (1-4), 488-494. doi: 10.1016/j.nimb.2005.04.025.

(70) Stephenson, C. V.; Lacey, J. C.; Wilcox, W. S. Ultraviolet Irradiation of Plastics III. Decomposition Products and Mechanisms. J. Polym. Sci. 1961, 55 (162), 477-488. doi: 10.1002/pol.1961.1205516206.

(71) Irusta, L.; Fernandez-Berridi, M. J. Photooxidative Behaviour of Segmented Aliphatic Polyurethanes. Polym. Degrad. Stab. 1999, 63 (1), 113-119. doi: 10.1016/So141-3910(98)ooo73-1.

(72) Scholz, P.; Wachtendorf, V.; Panne, U.; Weidner, S. M. Degradation of MDI-Based Polyether and Polyester-Polyurethanes in Various Environments - Effects on Molecular Mass and Crosslinking. Polym. Test. 2019, 77, 105881. doi: 10.1016/j.polymertesting.2019.04.028.

(73) Scholz, P.; Wachtendorf, V.; Elert, A. M.; Falkenhagen, J.; Becker, R.; Hoffmann, K.; ReschGenger, U.; Tschiche, H.; Reinsch, S.; Weidner, S. Analytical Toolset to Characterize Polyurethanes after Exposure to Artificial Weathering under Systematically Varied Moisture Conditions. Polym. Test. 2019, 78, 105996. doi: 10.1016/j.polymertesting.2019.105996.

(74) Gerber, J.; Radke, W. Separation of Linear and Star-Shaped Polystyrenes by Two-Dimensional Chromatography. E-Polymers 2005, 5 (1), 44. doi: 10.1515/epoly.2005.5.1.474.

(75) Al Samman, M.; Radke, W.; Khalyavina, A.; Lederer, A. Retention Behavior of Linear, Branched, and Hyperbranched Polyesters in Interaction Liquid Chromatography. Macromolecules 2010, 43 (7), 3215-3220. doi: 10.1021/ma902537e.

(76) Lederer, A.; Elrehim, M. A.; Schallausky, F.; Voigt, D.; Voit, B. Molecular Weight and Contraction Factors of Hyperbranched Poly(Urea-Urethane)S. E-Polymers 2006, 6 (1), 1-14. doi: 10.1515/epoly.2006.6.1.510.

(77) Striegel, A. M.; Brewer, A. K. Hydrodynamic Chromatography. Annu. Rev. Anal. Chem. 2012, 5 (1), 15-34. doi: 10.1146/annurev-anchem-062011-143107.

(78) Isenberg, S. L.; Brewer, A. K.; Côté, G. L.; Striegel, A. M. Hydrodynamic versus Size Exclusion Chromatography Characterization of Alternan and Comparison to Off-Line MALS. Biomacromolecules 2010, 11 (9), 2505-2511. doi: 10.1021/bm100687b.

(79) Giddings, J. C. Field-Flow Fractionation: An Alternative to Size Exclusion Chromatography. In Size Exclusion Chromatography; Hunt, B. J., Holding, S. R., Eds.; Springer US: Boston, MA, 1989; pp 191-216. doi: 10.1007/978-1-4615-7861-1_8.

(8o) Wyatt, P. J. Light Scattering and the Absolute Characterization of Macromolecules. Anal. Chim. Acta 1993, 272 (1), 1-40. doi: 10.1016/ooo3-2670(93)80373-S.

(81) Wyatt, P. J. The "Size" of Macromolecules and Some Observations on Their Mass. J. Liq. Chromatogr. 1991, 14 (12), 2351-2372. doi: 10.108o/01483919108049696. 
(82) Geisler, M.; Lederer, A. Non-Parabolicity Correction for Fifty-Nine Solvents and a Retention Study for Strongly Distorted Flow-Profiles in Thermal Field-Flow Fractionation. J. Chromatogr. A 2020, 1621, 461082. doi: 10.1016/j.chroma.2020.461082.

(83) Hansen, M. E.; Giddings, J. C.; Schure, M. R.; Beckett, R. Corrections for Secondary Relaxation in Exponentially Programmed Field-Flow Fractionation. Anal. Chem. 1988, 60 (14), 1434-1442. doi: 10.1021/acoo165ao18.

(84) Čožíková, D.; Šílová, T.; Moravcová, V.; Šmejkalová, D.; Pepeliaev, S.; Velebný, V.; Hermannová, M. Preparation and Extensive Characterization of Hyaluronan with Narrow Molecular Weight Distribution. Carbohydr. Polym. 2017, 16o, 134-142. doi: 10.1016/j.carbpol.2016.12.045. 